\title{
When the fit between HR practices backfires: Exploring the interaction effects between rewards for and appraisal of knowledge behaviours on innovation
}

Tatiana Andreeva, Maynooth University, School of Business, Maynooth, Co. Kildare, Ireland

Mika Vanhala, School of Business and Management, Lappeenranta University of Technology, Lappeenranta, Finland

Anastasia Sergeeva, Vrije Universiteit Amsterdam, the Netherlands

Paavo Ritala and Aino Kianto, School of Business and Management, Lappeenranta University of Technology, Lappeenranta, Finland

Human Resource Management Journal, Vol 27, no 2, 2017, pages 209-227

This paper explores the idea that well-aligned HR practices may produce varied and even negative effects on innovation performance. To do so, we examine the interaction effect between rewards for and appraisal of knowledge behaviours on radical and incremental innovation outcomes. Drawing on the insights from the strategic HRM literature on the internal fit between HR practices, as well as the developments of the knowledge governance approach, we argue that rewards and appraisal applied together produce a setting that is conducive for deepening existing knowledge bases, but hindering for more distant and diverse knowledge search. Empirical test of these hypotheses using the data from 259 Finnish companies lends partial support for this argument. Intensive usage of appraisal of knowledge behaviours reduces the positive impact that rewards for such behaviours have on radical innovation. At the same time, rewards and appraisal do not intensify each other's effect on incremental innovation.

Contact: Tatiana Andreeva, Maynooth University, School of Business, Maynooth, Co. Kildare, Ireland. Email: tatiana.andreeva@nuim.ie

Keywords: incremental innovation; radical innovation; complementarity; reward; appraisal; knowledge management

\section{INTRODUCTION}

$\mathbf{W}$ ith the increased interest in managing innovation, the question of what would be the appropriate governance mechanisms to promote this type of performance arose. Recent literature on HRM and innovation suggests that HR practices can influence innovation by facilitating three knowledge processes: knowledge creation, transfer and implementation (Shipton et al., 2005; Kang et al., 2007; De Winne and Sels, 2010). Indeed, the key premise of knowledge-based view on innovation posits that innovation performance is a function of a firm's ability to manage, maintain, and create knowledge (Cohen and Levinthal, 1990; Nonaka and Takeuchi, 1995). Micro-foundations perspective further argues that these abilities are enacted by employees searching for new knowledge, generating new ideas, exchanging and recombining them to the organisational benefit (Foss, 2007; Foss et al., 2010), thus bringing HRM to the forefront (Felin et al., 2009; Minbaeva et al., 2009). 
Strategic HRM literature has argued that HR practices impact employee behaviours jointly rather than in isolation (e.g., Jiang, K. et al., 2012). In particular, strategic fit approach suggests that HR practices have a particularly powerful positive impact on organisational performance when they all are aligned between each other and towards the same strategic goal (Purcell, 1999). However, some voices also pointed to the potential downsides of such a strong fit (e.g. Boxall, 2011), for example, warning against the potential waste of resources with 'overdesigned' HR systems where extra HR practices do not add further value to the organisation (Delery, 1998). Strategic HRM research also suggested that some HRM configurations might be more conducive than others to different types of organisational performance, in particular, to different types of innovation: radical and incremental (Kang et al., 2007; Medcof and Song, 2013; Collins and Kehoe, 2016).

While HRM-innovation literature, exploring various ways to encourage employees to innovate, has started to examine the complementarity between HR practices (e.g. Shipton et al., 2006; Beugelsdijk, 2008; Foss et al., 2015), it has mainly implied that the combinatory effect of aligned practices would be positive and produce added value for organisation. It has, however, paid less attention to a more critical idea that even if the HR practices are aligned towards the same goal their combined effect on innovation may be insignificant or even negative. Several review pieces called for more research in this area (Laursen and Foss, 2013; Minbaeva, 2013), however, little empirical research has been forthcoming.

To address these research gaps, we focus on two HR practices, rewards and appraisal, internally aligned to encourage knowledge behaviours of employees, and explore their interaction effects on different types of innovation performance. We empirically examine their joint effects on firms' incremental and radical innovation, using the data from 259 Finnish companies. Our paper contributes to the strategic and internal fit literature by demonstrating that highly aligned HR practices may backfire when radical innovation is at stake. It also contributes to HRM for innovation literature, demonstrating that the same configuration of HR practices has different impact for incremental and radical innovation. Finally, it contributes to rewards for innovation stream of research, suggesting that to understand the impact of rewards on knowledge behaviours and innovation, it is critical to consider them in the context of other HR practices.

\section{HR PRACTICES FOR MANAGING KNOWLEDGE BEHAVIOURS AND INNOVATION}

Our starting point is that in order to understand how HRM can stimulate organisational innovation, it is important to distinguish between different types of innovation (radical and incremental), as well as recognise that different configurations of HR practices may have differential effects on these two types of innovation (Kang et al., 2007; Collins and Kehoe, 2016). The reasons for this are rooted in the specificity of individual behaviours that are critical components of innovation process, i.e. knowledge creation, knowledge sharing and knowledge implementation (Nonaka and Takeuchi, 1995; Alavi and Leidner, 2001; Shipton et al., 2005). The specificity of these behaviours makes the design of HR practices aimed to promote them challenging, and also may explain why such practices may have differential, and sometimes even insignificant or negative, effects on the ultimate innovation outcomes.

Knowledge creation, sharing and application involve a substantial amount of ambiguity, complexity, uncertainty and risks due to the very nature of knowledge (Foss, 2007). These characteristics make it challenging for an organisation to define performance standards of what, by whom, how and when has to be created, shared and applied, and to measure and control for implementation of such standards (Alvesson, 1993, 2001; Osterloh and Frey, 2000; 
Sewell, 2005; Foss, 2007). Moreover, knowledge behaviours are often to some extent discretionary or extra-role, i.e. fully dependent on the employees goodwill to engage in them, which adds to the difficulty of facilitating such behaviours via organisational incentives (Wasko and Faraj, 2005; Gagné, 2009; Kuvaas et al., 2012; Minbaeva et al., 2012; Lerchenmueller and Nembhard, 2015). At the same time, these characteristics create challenges for employees, as they have to navigate ambiguities of what and how they can, should or should not do with knowledge in order to be successful in their careers in the organisation (e.g., Alvesson, 2001). Therefore it is both very important and difficult for organisations to design HR practices in order to guide employees towards what sort of knowledge is important to be shared and created, align their knowledge behaviours with the organisational goals (Foss, 2007; Gottschalg and Zollo, 2007) and ultimately bring about innovation outcomes. Without such governance structures, for example, employees may be well engaged in knowledge sharing and creation, that would not create, however, any value for the company (e.g., Sue-Chan and Hempel, 2016).

Two HR practices that have been widely used to align the organisational goals and individual behaviours are rewards and performance appraisal. They do so by signalling expectations, encouraging certain behaviours and providing feedback and evaluations (DeNisi and Pritchard, 2006). From the knowledge-based perspective rewards for knowledge behaviours are aimed at encouraging and steering knowledge behaviours, recognising achievements in this area and thus facilitating organisational innovation (Bock et al., 2005; Cabrera et al., 2006; Foss et al., 2015; Andreeva and Sergeeva, 2016). Such rewards may include bonuses for new ideas or for useful application of recently acquired knowledge or public recognition of knowledge sharing activities. However, the effect of such rewards is a contested question. Research has widely recognised the tensions around rewards for both knowledge creation (e.g. Amabile, 1996; Li et al., 2016; Sue-Chan and Hempel, 2016) and knowledge sharing (Foss et al., 2015; Lerchenmueller and Nembhard, 2015; Andreeva and Sergeeva, 2016). Some of the explanations for inconsistent findings regarding the effect of rewards on knowledge behaviours suggest that additional contextual factors, in particular, organisational conditions, have to be considered to understand this effect (e.g. Gagné and Deci, 2005; Cerasoli et al., 2014). For example, Foss et al. (2015) theorise that rewards per se is an ambiguous HR practice that carries both 'informational' and 'controlling' messages for employees. When knowledge behaviours, mostly driven by intrinsic motivation, are at stake, such ambiguity brings risks: if the informational aspect of rewards dominates, it signals to employees the value and recognition of their competence and thus boosts their intrinsic motivation to engage in knowledge behaviours. If the controlling aspect is emphasised, this intrinsic motivation is hindered (Deci et al., 1999). Therefore, Foss et al. (2015) suggest that rewards for knowledge behaviours should be accompanied by other HR practices that can help employees to make sense of rewards.

Appraisal of knowledge behaviours refers to evaluating employees' engagement in the above mentioned knowledge behaviours (Shipton et al., 2005; Jiang, J. et al., 2012). For example, traditional 360 degrees appraisal tool may be adjusted to include questions on an employee's knowledge sharing behaviours, in particular with subordinates and peers, especially from other departments. In addition, annual performance reviews may include discussion of how actively an employee contributed to knowledge creation, sharing, and application in the organisation, what inhibited such behaviours and how they can be improved in the future. This HR practice has been less studied in relation to knowledge behaviours. The limited empirical evidence on its' effects finds both positive and negative effects (Shipton et al., 2006; Jiang, J. et al., 2012; Medcof and Song, 2013; Bednall et al., 2014). The findings from literature on appraisal in general, that points to ambiguities in interpretation of performance 
appraisal (Longenecker et al., 1987; Levy and Williams, 2004; DeNisi and Pritchard, 2006; Budworth et al., 2015), allow suggesting that similarly to rewards for knowledge behaviours, appraisal of knowledge behaviours needs to be considered in combination with other HR practices, and in particular with rewards as those two often go in tandem (Longenecker et al., 1987).

Following strategic fit literature in HRM, we argue that rewards for and appraisal of knowledge behaviours, when applied jointly, have a potential to produce interaction effect that guides and encourages knowledge behaviours of employees through creating a coherent and consistent message and thus helping them to navigate ambiguities of knowledge work. However, in line with the studies that point towards potential tensions among well-aligned HR practices (Delery, 1988; Boxall et al., 2011), in particular when knowledge behaviours and innovation are at stake (Minbaeva et al., 2009; Minbaeva, 2013; Andreeva and Sergeeva, 2016), we suggest that such interaction effects may also backfire, limiting the space for distant knowledge search. To explore this idea in more detail, we refer to another stream of strategic HRM literature that suggests that some HRM configurations might be more conducive than others to different types of organisational performance, in particular, to different types of innovation (Kang et al., 2007; Medcof and Song, 2013; Collins and Kehoe, 2016). Building on these ideas, we investigate in the next section how interaction between the rewards for and appraisal of knowledge behaviours can influence radical and incremental innovation.

\section{DIFFERENTIAL EFFECTS OF INTERNAL FIT: THE CASES OF RADICAL AND INCREMENTAL INNOVATION}

Previous literature suggests that different organisational strategies for innovating - focused on incremental or radical innovation - call for different HR configurations (Kang et al., 2007; Medcof and Song, 2013; Collins and Kehoe, 2016). The reasoning is based on the idea that depending on its' strategic priorities in innovating, an organisation needs to encourage different aspects of knowledge behaviours - for example, more recombination of existing knowledge or more search for the knowledge outside the firm's knowledge domain, and thus design different HR systems to support them. This literature also points to the differences in the levels of ambiguity in knowledge work that different innovation types bring about. Indeed, while knowledge-related ambiguities described above are inherent to all innovation processes, they apply to a different extent to radical and incremental innovation.

Building on this work, we suggest that differences in knowledge demands and ambiguities between incremental and radical innovation may lead to the differing interaction effects between rewards for and appraisal of knowledge behaviours. More specifically, we argue that the consistent message created by the joint application of rewards for and appraisal of knowledge behaviours is conducive only to incremental innovation. When radical innovation is the goal, such internal fit will create a negative effect on the innovation performance, due to the 'normative ordering' effect (Alvesson and Kärreman, 2007) of an internally aligned HRM system. In the following sections we explore this idea in detail.

\section{Positive influence of rewards and appraisal on incremental innovation}

Incremental innovation is characterised by small changes and developments to existing products and technologies (Abernathy and Clark, 1985; March, 1991). From knowledge perspective, it typically involves 'refining existing knowledge stocks and improving how they are used', as well as 'localized and in-depth search in a narrow range of knowledge domains so as to pursue well-defined solutions in the existing knowledge bases of the firm' (Kang et al., 
2007, p. 237). Therefore the ambiguity of incremental innovation is lower, and the innovation processes include (at least some) visibility over the expected outcomes. In this context, there are relatively more certainties and fewer risks around what is needed from employees. Thus, the behaviours conducive for such search are relatively easier to imagine, formulate and incorporate in the reward and appraisal system.

In this case, if an organisation rewards employees for these knowledge behaviours, this helps to set and communicate correct expectations of what sort of behaviours are desirable. If on top of that organisations also include knowledge behaviours in their performance appraisal system, then employees have even a clearer idea of organisational expectations and thus will strive to engage in these behaviours more. This reduces ambiguity of rewards for them (Foss et al., 2015) and also triggers even more goal-oriented efforts, where employees will be consciously striving to share more knowledge, suggest new ideas, etc. (Lerchenmueller and Nembhard, 2015). Thus, the combination of rewards and appraisal will likely give a clear direction for employees of what knowledge is valuable to share and what sort of new knowledge is valuable to create. In addition, stimulating lots of knowledge behaviours inside the firm will facilitate the social climate (Collins and Smith, 2006) and strong connections between employees (Kang et al., 2007) that are particularly conducive to knowledge recombination within the firm boundaries and production of redundant and well-understood knowledge. Further on, consistent HR practices help developing similar cognitive maps and common interpretations among employees (Bowen and Ostroff, 2004), that also facilitate exchange and recombination of existing knowledge and maintain the boundaries of the knowledge domain as relatively narrow.

To summarise, we suggest that joint application of rewards for and appraisal of knowledge behaviours will efficiently address the ambiguities of the incremental innovation process and steer employees' efforts towards this goal. Thus, we hypothesise that:

Hypothesis 1: Rewards for knowledge behaviours and performance appraisal of knowledge behaviours applied jointly have a positive effect on incremental innovation outcomes.

\section{Negative influence of rewards and appraisal on radical innovation}

Radical innovation, on the contrary, is characterised by major departures from existing products and markets (Abernathy and Clark, 1985). It is associated with a broader and more general search for knowledge that is unknown to a firm yet, and a firm may even not know what knowledge it has to look for and where (March, 1991; Benner and Tushman, 2003). It also involves more distant search that crosses various and diverse knowledge domains (McGrath, 2001; Zhou and Li, 2012). The results of such search may deviate significantly from the existing organisational rules and expectations (Csikszentmihalyi, 1997), while their potential and usefulness for an organisation might be unclear, especially in the short-term (March, 1991; Sue-Chan and Hempel, 2016). Therefore radical innovation involves a lot of uncertainty and ambiguity of what and how should be done by employees, what outcomes can be achieved, if any, as well as high risks of failing to achieve these outcomes.

Establishing rewards for knowledge behaviours in such a context helps signalling employees that their risky endeavours are supported by an organisation and to steer them towards organisational goals (Gottschalg and Zollo, 2007; Sue-Chan and Hempel, 2016). However, we argue that the joint presence of rewards for and appraisal of knowledge behaviours is likely to inhibit such distant search and knowledge diversity, and thus 
undermine the number of radically new ideas and 'out of the box' solutions. The reason for this is that the internal fit of these practices will likely to create a strong mental model and cognitive schema of appropriate knowledge behaviours (Alvesson and Kärreman, 2007; Ehrnrooth and Björkman, 2012). For example, Alvesson and Karreman (2007) show that the HRM systems that are highly consistent and coherent in their messages to employees also serve 'identity forming' function for employees, through 'normative ordering' and 'providing cognitive clues' of how to act competently in the organisation (Alvesson and Kärreman, 2007, p. 720). Similarly, Bowen and Ostroff (2004) argue that strong HR systems, that have high consistency and distinctiveness among their key characteristics, lead to development of 'similar causal maps' among employees and 'induce compliance and conformity through social influence' (p. 213). While this helps to exercise strong organisational control (Alvesson and Kärreman, 2007), such strong system simultaneously decreases the diversity, flexibility and deviation needed for exploration of radically new paths (March, 1991). For example, Kang et al. (2007) mention that actively stimulating a particular set of knowledge behaviours within the firm, while beneficial for deepening existing knowledge bases, can be detrimental for broadening the knowledge or going outside of existing knowledge domain, as they 'limit employees' opportunities to explore varied knowledge domains by locking them into narrow social circles' (p. 239). To summarise, we suggest that joint application of rewards for and appraisal of knowledge behaviours will reduce the ambiguities of the radical innovation process to the extent that inhibits this process. Thus, we hypothesise that:

Hypothesis 2: Rewards for knowledge behaviours and performance appraisal of knowledge behaviours applied jointly have a negative effect on radical innovation outcomes.

\section{METHOD}

\section{Sample}

We tested the hypotheses with survey data collected in Finland in 2013 by means of a structured survey, using the key-informant technique. The initial aim was to target all Finnish companies with at least 100 employees. We imposed the size limit in order to ensure that our responding companies have formal HR practices. The Intellia database was utilised to identify the companies. A total of 1523 companies were found to be eligible for our survey. All these firms were contacted by an external research company by telephone and the person in charge of the human resources was asked to respond to the questionnaire. Confidentiality was emphasised and a summary of the results was promised to the respondents. We received 259 responses, representing a response rate of 17.0 per cent. The most represented industries were manufacturing $(37.8 \%)$ and wholesale and retail trade $(16.2 \%)$. Other notable industries were services $(9.7 \%)$ and transportation and storage $(8.1 \%)$. Based on statistical comparison (the $\chi^{2}$ test) with our target population, we identified that manufacturing is over-represented and services are underrepresented in our dataset, as these industries form 29.8 and 13.5 per cent of the entire population of the Finnish companies with at least 100 employees, respectively. Due to the specifics of our data collection method (telephone interviews using external research services firm), we do not have information about the early and late respondents and thus could not assess the existence of late respondent bias. Most of the respondents held such positions as HR director or manager (77.9\%), other director or manager $(8.8 \%)$ or managing director $(6.9 \%)$, indicating their expertise and key position regarding the issues of human resource management practices and organisational performance. 


\section{Measures}

HR practices to promote knowledge behaviours As our study builds on the knowledge-based view of HRM, positing that HR practices influence organisational outcomes by facilitating three knowledge processes: knowledge creation, transfer and implementation (Nonaka and Takeuchi, 1995; Alavi and Leidner, 2001), we were looking for the scales that will explicitly address the focus of rewards and appraisal on these processes. We were not able to identify such scales in previous studies and thus developed the scales based on theoretical considerations from Nonaka and Takeuchi (1995), Alavi and Leidner (2001), as well as on HRM scales from Andreeva and Kianto (2012). To assess content validity of the scales, we used an international panel of experts to review the scales, and incorporated their suggestions. After that, in order to confirm the operational validity and psychometric robustness of the scales, we pre-tested the initial scales with the sample of Finnish managers ( $N=151)$. The three items for appraisal of knowledge behaviours incorporated contribution to knowledge behaviours as a criterion for performance assessment. Rewards for knowledge behaviours were measured by the three items covering contributions to these behaviours as a criterion for rewarding. All of the measures were based on a five-point Likert scale (1-strongly disagree, 5-strongly agree) and asked the respondents to assess to what extent the statements apply to their organisation. All the survey items, together with the respective factor loadings, are presented in the Appendix.

Radical and incremental innovation Innovation outcomes are challenging to measure, and there are no commonly adopted measurement practices for this purpose (Tomlinson, 2010). We chose to measure those as the subjective perceptions of respondents, having two reasons in mind. First, we needed an indicator that will be meaningful and applicable to all companies in our sample and second, we wanted to ensure comparability between different kinds of companies. Therefore, we had to reject some commonly used objective measures, e.g., number of patents, as they were not relevant for many sectors in our sample. Earlier research has demonstrated that measures of perceived performance correlate strongly and positively with objective measures (see e.g. Robinson and Pearce, 1988; Delaney and Huselid, 1996) and that combined with a rigorous research design perceptual data is an adequate option (e.g. Howard, 1994; Minbaeva et al., 2012). In addition, we consulted with the practitioners and experts in the field asking them if such perceptual measures capture the innovation outcomes, and these discussions provided further backup for our measures.

We used one-item measures for the incremental and radical innovation (see the Appendix), whereby we asked respondents to evaluate the effect of their company's radical and incremental innovations on the firm's net sales over the past year (1 - no effect, 5 - significant positive effect). Measuring the incremental and radical innovation with single-item measures has been used frequently in earlier innovation and HRM literature (see e.g., Beugelsdijk, 2008; Tomlinson, 2010; Ritala and Hurmelinna-Laukkanen, 2013), and we chose to follow these examples.

Control variables We used four variables (age of the company, number of personnel, industry type and R\&D intensity) as the control variables in order to account for the effect they might have on the innovations of the company (Tu and Hall, 2004). Firm age was measured in terms of number of years since establishment and the number of employees was utilised as a proxy value for the firm size. Industry type was an adapted classification of the 8 groups from the NACE coding. The R\&D intensity was reported by the respondents as a percentage of research and development staff of all employees in 2012. We used the natural logarithmic transformation of the variable for the analysis. 
We used partial least squares (PLS) for the analysis (version 2.0M3 of SmartPLS) and followed the process suggested in the literature (see e.g., Hair et al., 2014). The first step was to assess the reliability and validity of the measurement models. We then used the structural model to test our hypotheses. In order to analyse interaction effects, the direct relations of the variables and also the relation of the interaction term were examined (Aiken and West, 1991; Hayes, 2013).

Validity and reliability of the measures As a first step of our analysis, we assessed the internal consistency and the discriminant validity of the used multi-item scales. Measures of construct reliability (CR) and convergent validity of our scales are presented in the Appendix. All the constructs showed a CR value above the threshold (0.7, adopted by Bagozzi and Yi, 1991), and the AVE measure of all our constructs exceeded the cut-off $(0.5$, see e.g., Fornell and Larcker, 1981). Further on, AVEs for our constructs were greater than the squared correlation between two constructs (see Table 1), demonstrating discriminant validity of our constructs (Fornell and Larcker, 1981). In sum, the model assessments gave good evidence of validity and reliability of the operationalisation of the concepts.

Assessment of common method bias Designing our study, we took several steps to ensure that common method bias (CMB) would not influence our results, following the guidelines in the literature (Podsakoff et al., 2012) as well as example of previous studies (cf. Minbaeva et al., 2012). First, during the design and administration of the survey the respondent confidentiality was explicitly assured. This served the purpose of reducing risk of CMB by making respondents less likely to alter their answers due to how they think others may expect them to answer. Second, we improved the scale items in collaboration with the practitioners in the field. This helped us to use clear wordings and keep the survey compact. Third, our survey involved highly experienced (related to the topic) respondents to evaluate study constructs in order to decrease the possibility of CMB. Fourth, for the same purpose we used varied anchoring of the scales in our survey (different anchors for HR practices and for innovation measures).

Finally, after data collection we performed statistical analyses in order to assess the possibility of such bias. As suggested by Podsakoff et al. (2012), we tested a measurement model including an unmeasured latent factor method (representing common method variance). In this model items were allowed to load both on their theoretical constructs and on a common method factor (see Liang et al., 2008). The loadings on the method factor were substantially lower than the loadings on the construct factors indicating the non-existence of the CMB. Taken together these design and statistical measures suggest that common method bias is unlikely to be a serious concern in this study.

\section{Correlation analysis}

Table 2 presents the means and standard deviations, and provides a correlation matrix. As the matrix shows, there are significant correlations between the independent variables (i.e., rewards for and appraisal of knowledge behaviours) and the dependent variables (i.e., incremental and radical innovation).

\section{Testing the research models}

In order to test our hypotheses, we estimated path models reflecting the posited relationships between HR practices, the interactions of the practices, and both incremental and radical 
TABLE 1 Discriminant validity

\begin{tabular}{llc}
\hline \multicolumn{1}{c}{ Variable } & $\mathbf{1}$ \\
& & $\mathbf{2}$ \\
1 & Appraisal of knowledge behaviours & $\mathbf{0 . 7 2}$ \\
2 & Rewards for knowledge behaviours & 0.31 \\
Notes: AVE associated with the construct is presented diagonally. The squared correlations between the constructs are \\
presented in the lower left triangle.
\end{tabular}

TABLE 2 Correlation matrix

\begin{tabular}{|c|c|c|c|c|c|c|c|c|c|}
\hline Variable & Mean & SD & 1 & 2 & 3 & 4 & 5 & 6 & 7 \\
\hline 1. Employees & 386.39 & 688.17 & & & & & & & \\
\hline 2. Age & 28.50 & 25.09 & $0.140^{*}$ & & & & & & \\
\hline 3. Industry & 5.59 & 2.21 & -0.037 & 0.099 & & & & & \\
\hline 4. R\&D Intensity & 5.78 & 11.06 & 0.17 & 0.066 & -0.037 & & & & \\
\hline 5. Appraisal of knowledge behaviours & 2.88 & 0.97 & 0.063 & $0.122^{*}$ & 0.019 & $0.183^{* *}$ & & & \\
\hline 6. Rewards for knowledge behaviours & 2.63 & 1.12 & 0.068 & 0.047 & -0.091 & $0.293^{* *}$ & $0.552^{* *}$ & & \\
\hline 7. Radical innovation & 2.36 & 1.54 & 0.011 & 0.049 & -0.023 & $0.226^{* *}$ & $0.247^{* *}$ & $0.359^{* *}$ & \\
\hline 8. Incremental innovation & 2.64 & 1.53 & 0.045 & 0.024 & 0.022 & $0.226^{* *}$ & $0.326^{* *}$ & $0.348^{* *}$ & $0.674^{* *}$ \\
\hline \multicolumn{10}{|l|}{ Notes: } \\
\hline \multicolumn{10}{|c|}{ ** Correlation is significant at the 0.05 level; } \\
\hline * Correlation is significant at the 0.01 le & & & & & & & & & \\
\hline
\end{tabular}

innovation, following the procedures suggested in the literature (see e.g., Hair et al., 2014). As Tables 3 and 4 show, our research models could explain around 17 and 16 per cent of the variance of the incremental and radical innovation, respectively.

In the incremental innovation direct effect model (see Table 3, Model 1) the path estimates from both appraisal of knowledge behaviours $(B=0.168, p<0.05)$ as well as rewards for knowledge behaviours $(B=0.239, p<0.005)$ to incremental innovation were significant and had a positive impact. However, interaction effect between two HR practices was not significant (see Table 3, Model 2). Thus, Hypothesis 1 was not supported.

In the radical innovation direct effect model (see Table 4, Model 1) only rewards for knowledge behaviours had a direct effect on radical innovation $(B=0.287, p<0.005)$. In the interaction model for radical innovation (see Table 4, Model 2) there was statistically significant relationships between interaction term and radical innovation. The path estimate from interaction of rewards and performance appraisals to radical innovation was statistically significant and negative $(B=-0.131, p<0.05)$. Thus, Hypothesis 2 was supported: in the case of radical innovation, two HR practices interact negatively, weakening the effect of each other on radical innovation.

We applied the Johnson-Neyman technique, or floodlight analysis (Hayes, 2013; Spiller et al., 2013) to decompose this interaction effect and identify ranges of performance appraisal at which rewards affect radical innovation differently. This analysis revealed two focal cut-points, dividing our dataset into three sub-samples: a group with the performance appraisal score 
TABLE 3 Testing the incremental innovation models

\begin{tabular}{|c|c|c|c|}
\hline Dependent variable - Incremental innovation & Model 0 & Model 1 & Model 2 \\
\hline \multicolumn{4}{|l|}{ Independent variables } \\
\hline \multicolumn{4}{|l|}{ Controls } \\
\hline Employees & 0.043 & 0.022 & 0.022 \\
\hline Age & -0.000 & -0.029 & -0.029 \\
\hline Industry & 0.032 & 0.050 & 0.051 \\
\hline R\&D Intensity & $0.227^{* * *}$ & $0.133^{* *}$ & $0.129^{* *}$ \\
\hline \multicolumn{4}{|l|}{ Direct effects } \\
\hline Appraisal of knowledge behaviours & & $0.168^{* *}$ & $0.153^{* *}$ \\
\hline Rewards for knowledge behaviours & & $0.239^{* * * *}$ & $0.240^{* * *}$ \\
\hline \multicolumn{4}{|l|}{ Interaction effect } \\
\hline Rewards for knowledge behaviours $\times$ Appraisal of knowledge behaviours & & & -0.039 \\
\hline$R^{2}$ & 0.054 & 0.174 & 0.175 \\
\hline $\begin{array}{l}\text { Notes: } \\
* * * \text { Significance }<0.005 ; \\
* * \text { Significance }<0.05\end{array}$ & & & \\
\hline
\end{tabular}

TABLE 4 Testing the radical innovation models

\begin{tabular}{|c|c|c|c|}
\hline Dependent variable - Radical innovation & Model 0 & Model 1 & Model 2 \\
\hline \multicolumn{4}{|l|}{ Independent variables } \\
\hline \multicolumn{4}{|l|}{ Controls } \\
\hline Employees & 0.001 & -0.016 & -0.015 \\
\hline Age & 0.036 & 0.015 & 0.018 \\
\hline Industry & -0.018 & 0.007 & 0.009 \\
\hline R\&D Intensity & $0.223^{* * *}$ & $0.135^{* *}$ & 0.119 \\
\hline \multicolumn{4}{|l|}{ Direct effects } \\
\hline Appraisal of knowledge behaviours & & 0.063 & 0.010 \\
\hline Rewards for knowledge behaviours & & $0.287^{* * *}$ & $0.291^{* * *}$ \\
\hline \multicolumn{4}{|l|}{ Interaction effect } \\
\hline Rewards for knowledge behaviours $\times$ Appraisal of knowledge behaviours & & & $-0.131^{* *}$ \\
\hline$R^{2}$ & 0.053 & 0.150 & 0.164 \\
\hline \multicolumn{4}{|l|}{ Notes: } \\
\hline$* * *$ Significance $<0.005$ & & & \\
\hline$* *$ Significance $<0.05$ & & & \\
\hline
\end{tabular}

below 2.59 (sample size: 73 , mean $=1.83, \mathrm{SD}=0.62$ ), a group with a score between 2.59 and 3.72 (sample size: 151 , mean $=3.18, \mathrm{SD}=0.35$ ) and group with a score above 3.72 (sample size: 32 , mean $=4.20, \mathrm{SD}=0.35$ ). Taking into account the anchoring of our scale, where 1 meant 'strongly disagree' that HR practice is used in a company, and 5 meant 'strongly agree', we interpret these groups as low, medium and high level of usage of appraisal for knowledge.

Next, we tested the direct effect of rewards for knowledge behaviours on radical innovation in these sub-groups (see Table 5). In the group with a low level of usage of performance appraisal, the path from rewards for knowledge behaviours to radical innovation was positive $(\mathrm{B}=0.546, p<0.005)$. In the group of high usage of appraisal of knowledge behaviours the path was still significant and positive, but the size of the effect was lower $(B=0.342, p<0.005)$. In the 
TABLE 5 Testing the sub-group models for radical innovation

\begin{tabular}{|c|c|c|c|}
\hline \multicolumn{4}{|c|}{ Dependent variable - Radical innovation } \\
\hline & $\begin{array}{l}\text { Low level of usage of appraisal } \\
\text { of knowledge behaviours } \\
(\mathrm{N}=73)\end{array}$ & $\begin{array}{l}\text { Medium level of usage of } \\
\text { appraisal of knowledge } \\
\text { behaviours ( } N=151)\end{array}$ & $\begin{array}{l}\text { High level of usage of appraisal } \\
\text { of knowledge behaviours } \\
(\mathrm{N}=32)\end{array}$ \\
\hline \multicolumn{4}{|l|}{ Independent variables } \\
\hline \multicolumn{4}{|l|}{ Controls } \\
\hline Employees & 0.038 & $-0.185^{*}$ & 0.089 \\
\hline Age & $0.126^{* *}$ & 0.045 & 0.019 \\
\hline Industry & -0.035 & -0.041 & 0.049 \\
\hline R\&D Intensity & $0.237^{* * *}$ & -0.041 & $0.289^{*}$ \\
\hline \multicolumn{4}{|l|}{ Direct effects } \\
\hline $\begin{array}{l}\text { Rewards for } \\
\text { knowledge behaviours }\end{array}$ & $0.546^{* * *}$ & 0.059 & $0.342^{* * * *}$ \\
\hline$R^{2}$ & 0.457 & 0.040 & 0.263 \\
\hline $\begin{array}{l}\text { Notes: } \\
* * * \text { Significance }<0.005 ; \\
* * \text { Significance }<0.05 \\
* \text { Significance }<0.10\end{array}$ & & & \\
\hline
\end{tabular}

group of medium usage of appraisal the effect of rewards on innovation turned insignificant $(B=0.059)$. Furthermore, following the guidance by Lowry and Gaskin (2014) we tested whether the size of the effect (i.e. path between rewards and radical innovation) was significantly lower in the groups of medium and high usage of appraisal compared to the group of low. The differences between medium and low usage groups (0.487) and medium and high usage groups (0.283) were statistically significant $(p<0.005$ and $p<0.05$, respectively). The difference between the groups of low and high usage of appraisal was not statistically significant.

Thus, the results illustrate how appraisal of knowledge behaviours affects the relationship between rewards for knowledge behaviours and radical innovation. If the level of usage of performance appraisal is low, then the effect of rewards on radical innovation is the strongest. However, when the level of usage of performance appraisal is high, the effect of rewards on radical innovation becomes weaker, and turns insignificant when the usage of appraisal is medium. Figure 1 schematically illustrates these findings.

In sum, our findings show that rewards and performance appraisal targeted to promote knowledge behaviours have different effects on incremental and radical innovation performance. Our major focus was on the potential interaction effects between two HR practices, in terms of how they jointly stimulate innovative outcomes of different types.

For incremental innovation our findings suggest that while both rewards for knowledge behaviours and relevant appraisal have positive effects on this type of innovation, there are neither positive nor negative interactions among them. It means that both practices can be useful for promoting incremental innovation, but their joint application does not create additional value beyond their direct effects. In other words, firms that apply both practices simultaneously are not more successful in incremental innovations than the firms that apply only, for instance, rewards for knowledge behaviors. We suggest two potential explanations for this finding. First, application of either rewards or (to a lesser extent) performance appraisal on their own might be sufficient to provide a clear enough direction for employees and mitigate 
FIGURE 1 The impact rewards for knowledge behaviours on radical innovation at the different levels of usage of performance appraisal of knowledge behaviours

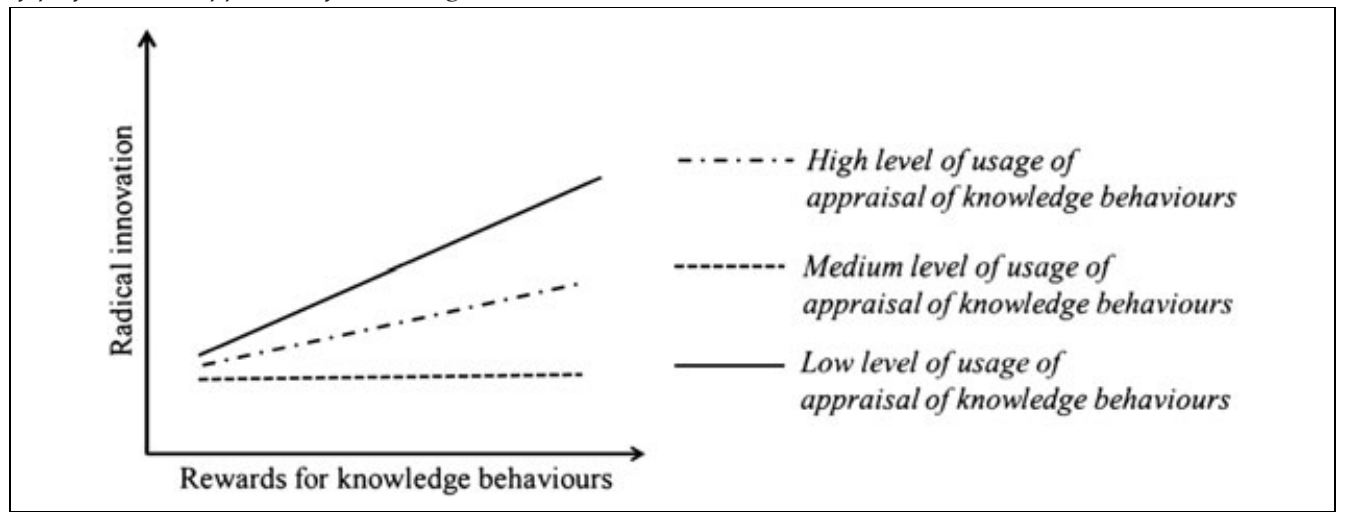

the ambiguity related to incremental innovation. In this case provision of additional clarification through the second HR practice does not add more value. Second, this finding can be also explained by the peculiarities of the context of our study, as our sample includes quite a big share of manufacturing companies (37.8\%). Manufacturing can be a sector where it is relatively easier to formulate clearly the goals of incremental innovation and thus the need for decreasing ambiguity by HRM practices may be lower.

On the other hand, for radical innovation, rewards for knowledge behaviours negatively interact with performance appraisal. This means that introducing appraisal of knowledge behaviours downplays the effectiveness of rewards for knowledge behaviours in the context of promoting radical innovation outcomes. Interestingly, we found that in the group with medium level of usage of appraisal the effect of rewards on radical innovation was insignificant. A potential explanation for this finding might be that the medium level reflects situations when a company applies appraisal, but perhaps inconsistently, which may create confusion among employees regarding what the organisation actually values and expects from them, thus undermining the potential signalling effect of rewards.

\section{IMPLICATIONS FOR THEORY AND PRACTICE}

This study focuses on two HR practices - rewards for and appraisal of knowledge behaviours and examines the effect these two practices, applied jointly, have on incremental and radical innovation. We argue that joint application of rewards and appraisal can be conducive for incremental innovation, but not for the radical one. This is because of their function as 'normative ordering' devices, provision of 'cognitive cues' of appropriate behaviour and creating strong shared mental models (Alvesson and Kärreman, 2007), that inadvertently limits knowledge search within certain domain. Such conditions are favourable for incremental innovation and detrimental for the radical one (March, 1991; Kang et al., 2007). Our empirical findings confirm our reasoning regarding the negative impact of the joint application of two HR practices, focused on knowledge behaviours, on radical innovation, but lend no support to its positive effect for the incremental.

This study informs several discussions in the literature. To start with, we make several contributions to the literature focusing on how HRM can facilitate innovation. First, we demonstrate the importance of studying innovation-enhancing HR practices in bundles rather 
than in isolation, and accounting for tensions within such bundles. Indeed, previous research has examined how various HR practices, for example, rewards and recognition, training and job design promote and support innovation performance (Laursen and Foss, 2003; Shipton et al., 2005; Shipton et al., 2006; Jiménez-Jiménez and Sanz-Valle, 2008; Beugelsdijk, 2008; Lopez-Cabrales et al., 2009; De Winne and Sels, 2010). While these studies have provided valuable insights into how HR practices can foster innovative outcomes, they have paid relatively less attention to how different components of HRM systems work in combinations to produce these results (e.g. Laursen and Foss, 2013). Our study extends this literature theoretically and empirically by exploring why combinations of HR practices may be particularly impactful, or sometimes detrimental, for innovation outcomes, using the insights from strategic HRM and knowledge governance theories.

Second, we contribute to the debate on the impact of rewards on innovation (Beugelsdijk, 2008; Lopez-Cabrales et al., 2009; Curran and Walsworth, 2014). Previous empirical research has produced various results and explanations regarding the effectiveness of paying employees to innovate, for example in creativity studies (Amabile, 1996; Sue-Chan and Hempel, 2016). The results have been both negative (e.g., Amabile, 1996) and positive (Zhao and Chadwick, 2014). The inconsistency of these findings can be explained by the fact that the rewards have rarely been studied in conjunction with another HR practice that has a potential to incentivise and guide employees' knowledge behaviour, such as appraisal. Yet appraisal is very commonly applied in tandem with the reward system (Longenecker et al., 1987) and is likely to be intertwined with rewards. Our empirical findings thus extend this literature by demonstrating that the effectiveness of rewards is dampened by the introduction of appraisal when radical innovation outcomes are at stake. This way we provide evidence for the idea that to understand the impact of rewards on knowledge-related behaviours and innovation, it is critical to consider them jointly with other HR practices, especially with appraisal.

Third, our results inform the discussion on how HRM mechanisms can facilitate various types of innovation (Beugelsdijk, 2008; Laursen and Foss, 2013). In particular, they extend the emerging discussions about strategic HRM configurations for innovation, that argues that different innovation strategies - radical and incremental innovation focus - call for different HR approaches (Kang et al., 2007; Collins and Kehoe, 2016). Empirical studies in this area are scarce, and our paper provides evidence demonstrating that the same configuration of HR practices indeed has different impact on incremental and radical innovation.

Our paper also contributes to the strategic HRM literature by demonstrating that highly aligned HR practices may bring not only positive, but also no or negative results. This literature has emphasised that HR practices are not applied in a vacuum, but rather work in bundles and create complementarities (e.g., Jiang, K. et al., 2012). Generally, the underlying argument was related to the fit between practices and their alignment with the strategic objectives of organisations that can create value beyond the effects of single practices (e.g. Purcell, 1999). Following this logic, the conflicts between HR practices are expected to happen when the practices lack such an alignment. Contrary to these expectations, our study suggests that even if HR practices are aligned towards the same goal, their combinatory effect may be insignificant or even negative. This is in line with some recent critical concerns regarding the overly idealistic pictures of such fit and alignment (e.g., Boxall et al., 2011), as well as recent findings regarding the negative effects of strong HR systems on innovation (Bednall et al., 2014). Our study extends this critical view with a novel theoretical explanation of such negative effects, rooted in the peculiarities of knowledge behaviours and knowledge-intensive outcomes. We do this by putting forward an argument that internally aligned HR systems with their normative ordering can be too strong and thus limit the diversity and experimentation needed for radical innovation. 
Last, but not the least, our study contributes to the knowledge governance and HRM literature dealing with the effects of organising on knowledge behaviours and ultimately knowledge-based outcomes. The work in this area is growing and increasingly mindful of various pitfalls and difficulties of designing HRM for such behaviours as knowledge sharing or knowledge creation, due to their ambiguity, complexity, collective and interdependent nature and fragility of their motivational foundations (Osterloh and Frey, 2000; Foss et al., 2009; Andreeva and Sergeeva, 2016). Yet research in this area has only started to address potential controversies and contradictions among HR practices for managing knowledge and raised the question whether having more HR practices in this area is always better (Minbaeva, 2013; Andreeva and Sergeeva, 2016). Our findings add to this conversation by demonstrating that having more HR practices to encourage knowledge behaviours does not always pay off, particularly in the case of radical innovation. Our study also suggests that the challenges of rewards in knowledge governance are not only related to the widely discussed motivational issues (Osterloh and Frey, 2000), but also to the effects of the HR systems for strengthening common schemas and normative ordering, which can hinder the amount of exploration and search for 'out of the box', radically new solutions.

Finally, on the practical side, our findings suggest that if managers aim to promote radical innovation, they should strive to provide rewards for knowledge behaviours, and avoid introducing appraisal for such behaviours. Introducing these two practices simultaneously may lead to spending organisational resources in vain, because appraisal reduces the positive effects of rewards. Alternatively, if managers aim to promote incremental innovation, they can apply either rewards or appraisal. Implementing either one of these mechanisms is sufficient for stimulating knowledge behaviours, needed to generate incremental innovations. Yet, as the effect of rewards is stronger, when the situation allows for it, it is more beneficial to use rewards rather than appraisal for encouraging incremental innovation. On a more general note, the results also suggest that the managers should refrain from overdesigning HR practices, especially when striving for radical, out-of-the-box solutions. In such cases, it may be more beneficial to leave some openness and ambiguity regarding what knowledge outcomes are valued, in order to promote diversity and achieve truly radical innovation.

\section{Limitations and future research questions}

When interpreting the findings of this study, one needs to acknowledge some limitations. First, our data is of a cross-sectional nature and thus the scope of the conclusions regarding causal relationships between the variables in the model is limited. Our respondents reported their perceptions of current HR practices aimed to stimulate knowledge behaviours and levels of incremental and radical innovation simultaneously. While the mainstream HRM literature implies that certain HR practices lead to innovative results, alternative causal explanations may also exist (e.g., Paauwe and Richardson, 1997). For example, companies that are more successful in radical innovations may favour rewards above other HR practices because they have more resources at hand thanks to premium rents gained from radical innovations (e.g., Park and Kruse, 2014).

Second, some researchers argue that HR practices have not an immediate but a long-term effect on performance (Paauwe and Boselie, 2005). Such an effect could not be captured in our dataset. Based on these two concerns, future research would benefit from a longitudinal study that tracks the changes in innovation performance after the implementation of the HR practices aimed to encourage knowledge behaviours. 
Third, our data includes only managerial perceptions of HR practices and does not cover the employee perceptions of these practices, or their behavioural reactions to them (Nishii et al., 2008). Indeed, managers' vision about HR practices might differ from employee perceptions of these practices and managerial intentions behind them. The deeper understanding of reasons behind the relationships between HR practices aimed to encourage knowledge behaviours and innovation calls for further research on micro-foundations of this link (Minbaeva, 2013).

Finally, the scope of future studies can be expanded beyond the focus only on HR practices aimed to incentivise and guide knowledge behaviours. For example, recent research suggests that opportunities for knowledge sharing may turn extrinsic rewards futile (Andreeva and Sergeeva, 2016). Therefore, the question of how incentivisation-focused HR practices interact not only with each other but also with other HR practices deserves further discussion.

\section{CONCLUSION}

This study examined how two HR practices aimed to encourage and guide knowledge behaviours - rewards and performance appraisal - interact to affect incremental and radical innovations of a firm. Our empirical findings demonstrate that for incremental innovation these two practices do not produce any additional positive interaction effect, while both of them influence it positively directly. However, in the case of radical innovation rewards for knowledge behaviours and appraisal for knowledge behaviours interact negatively, whereby the positive effect of rewards is reduced by introduction of performance appraisal. Overall, these results provide a new understanding of the complex interrelationships between HR practices, knowledge behaviours and innovation in organisations.

\section{Conflicts of interest}

There are no conflicts of interests related to this study.

\section{Funding}

The data utilised in this paper was based on a project funded by Tekes - the Finnish Funding Agency for Innovation. We wish to express our gratitude for Tekes in this regard.

\section{Acknowledgements}

We would like to thank Special Issue editorial team, and especially Helen Shipton, as well as three anonymous reviewers of Human Resource Management Journal for their constructive feedback on previous drafts of this article. We also would like to thank Paul Hempel for the developmental comments on the earlier version of this paper, offered at the Academy of Management annual meeting in 2015. Finally, we would like to thank Joseph Coughlan, Christian Martin, Peter McNamara and Olga Ryazanova, first author's colleagues at Maynooth University, for their advice on methodological issues.

\section{REFERENCES}

Abernathy, W.J. and Clark, K.B. (1985). 'Innovation: Mapping the winds of creative destruction'. Research Policy, 14: 1, 3-22.

Aiken, L.S. and West, S.G. (1991). Multiple Regression: Testing and Interpreting Interactions, Newbury Park, CA: Sage.

Alavi, M. and Leidner, D. (2001). 'Review: Knowledge management and knowledge management systems: Conceptual foundations and research issues'. MIS Quarterly, 25: 1, 107-136. 
Alvesson, M. (1993). 'Organizations as rhetoric: knowledge-intensive firms and the struggle with ambiguity'. Journal of Management Studies, 30: 6, 997-1015.

Alvesson, M. (2001). 'Knowledge work: Ambiguity, image and identity'. Human Relations, 54, 863-886.

Alvesson, M. and Kärreman, D. (2007). 'Unraveling HRM: Identity, ceremony, and control in a management consulting firm'. Organization Science, 18: 4, 711-723.

Amabile, T.M. (1996). Creativity in Context, Boulder, CO: Westview Press.

Andreeva, T. and Kianto, A. (2012). ‘Does knowledge management really matter? Linking knowledge management practices, competitiveness and economic performance'. Journal of Knowledge Management, 16: 4, 617-636.

Andreeva, T. and Sergeeva, A. (2016). 'The more the better... Or is it? The contradictory effects of HR practices on knowledge sharing motivation and behavior'. Human Resource Management Journal, 26: 2, 151-171.

Bagozzi, R.P. and Yi, Y. (1991). 'Multitrait-multimethod matrices in consumer research'. Journal of Consumer Research, 17: 4, 426-439.

Bednall, T.C., Sanders, K. and Runhaar, P. (2014). 'Stimulating informal learning activities through perceptions of performance appraisal quality and HRM system strength: A two-wave study'. Academy of Management Learning E Education, 13: 1, 45-61.

Benner, M. and Tushman, M. (2003). 'Exploitation, exploration, and process management: The productivity dilemma revisited'. Academy of Management Review, 28: 2, 238-256.

Beugelsdijk, S. (2008). 'Strategic human resource practices and product innovation'. Organization Studies, 29: 6, 821-847.

Bock, G.W., Zmud, R.W., Kim, Y.G. and Lee, J.N. (2005). 'Behavioral intention formation in knowledge sharing: Examining the roles of extrinsic motivators, social-psychological forces, and organizational climate'. MIS Quarterly, 29: 1, 87-111.

Bowen, D.E. and Ostroff, C. (2004). 'Understanding HRM-firm performance linkages: The role of the "strength" of the HRM system'. Academy of Management Review, 29: 2, 203-221.

Boxall, P., Ang, S.H. and Bartram, T. (2011). 'Analysing the "black box" of HRM: Uncovering HR goals, mediators, and outcomes in a standardized service environment'. Journal of Management Studies, 48: 7, 1504-1532.

Budworth, M.-H., Latham, G.P. and Manroop, L. (2015). 'Looking forward to performance improvement: A field test of the feedforward interview for performance management'. Human Resource Management, 54: $1,45-54$.

Cabrera, A., Collins, W.C. and Salgado, J.F. (2006). 'Determinants of individual engagement in knowledge sharing'. International Journal of Human Resource Management, 17: 2, 245-264.

Cerasoli, C.P., Nicklin, J.M. and Ford, M.T. (2014). 'Intrinsic motivation and extrinsic incentives jointly predict performance: A 40-year meta-analysis'. Psychological Bulletin, 140: 4, 980-1008.

Cohen, W.M. and Levinthal, D.A. (1990). 'Absorptive capacity: A new perspective on learning and innovation'. Administrative Science Quarterly, 35: 1, 128-152.

Collins, C. and Kehoe, R. (2016) 'Examining strategic fit and misfit in the management of knowledge workers', ILR Review, doi: 10.1177/0019793916654481.

Collins, C.J. and Smith, K.G. (2006). 'Knowledge exchange and combination: The role of human resource practices in the performance of high-technology firms'. Academy of Management Journal, 49: 3, 544-560.

Csikszentmihalyi, M. (1997). Creativity: Flow and the Psychology of Discovery and Invention, New York: HarperCollins.

Curran, B. and Walsworth, S. (2014). 'Can you pay employees to innovate? Evidence from the Canadian private sector'. Human Resource Management Journal, 24: 3, 290-306.

De Winne, S. and Sels, L. (2010). 'Interrelationships between human capital, HRM and innovation in Belgian start-ups aiming at an innovation strategy'. International Journal of Human Resource Management, 21: 11, 1863-1883.

Deci, E.L., Koestner, R. and Ryan, R.M. (1999). 'A meta-analytic review of experiments examining the effects of extrinsic rewards on intrinsic motivation'. Psychological Bulletin, 125: 6, 627-668. 
Delaney, J.T. and Huselid, M.A. (1996). 'The impact of human resource management practices on perceptions of organizational performance'. Academy of Management Journal, 39: 4, 949-969.

Delery, J. (1998). 'Issues of fit in strategic human resource management: Implications for research'. Human Resource Management Review, 8: 3, 289-309.

DeNisi, A.S. and Pritchard, R.D. (2006). 'Performance appraisal, performance management and improving individual performance: A motivational framework'. Management and Organization Review, 2: 2, 253-277.

Ehrnrooth, M. and Björkman, I. (2012). 'An integrative HRM process theorization: Beyond signalling effects and mutual gains'. Journal of Management Studies, 49: 6, 1109-1135.

Felin, T., Zenger, T.R. and Tomsik, J. (2009). 'The knowledge economy: Emerging organizational forms, missing microfoundations, and key considerations for managing human capital'. Human Resource Management, 48: 4, 555-570.

Fornell, C. and Larcker, D.F. (1981). 'Evaluating structural equation models with unobservable variables and measurement error'. Journal of Marketing Research, 18: 1, 39-50.

Foss, N. (2007). 'The emerging knowledge governance approach: Challenges and characteristics'. Organization, 14: 1, 29-52.

Foss, N., Minbaeva, D., Pedersen, T. and Reinholt, M. (2009). 'Encouraging knowledge sharing among employees: How job design matters'. Human Resource Management, 48: 6, 871-893.

Foss, N., Husted, K. and Michailova, S. (2010). 'Governing knowledge sharing in organizations: Levels of analysis, governance mechanisms and research directions'. Journal of Management Studies, 47: 3, 455-482.

Foss, N., Pedersen, T., Reinholt Fosgaard, M. and Stea, D. (2015). 'Why complementary HRM practices impact performance: The case of rewards, job design, and work climate in a knowledge-sharing context'. Human Resource Management, 54: 6, 955-976.

Gagné, M. (2009). 'A model of knowledge-sharing motivation'. Human Resource Management, 48: 4, 571-589.

Gagné, M. and Deci, E. (2005). 'Self-determination theory and work motivation'. Journal of Organizational Behavior, 26: 4, 331-362.

Gottschalg, O. and Zollo, M. (2007). 'Interest alignment and competitive advantage'. Academy of Management Review, 32: 2, 418-437.

Hair, J.F., Sarstedt, M., Hopkins, L. and Kuppelwieser, V.G. (2014). 'Partial least squares structural equation modeling (PLS-SEM) - An emerging tool in business research'. European Business Review, 26: 2, 106-121.

Hayes, A.F. (2013). Introduction to Mediation, Moderation and Conditional Process Analysis: A Regression Based Approach, New York: The Guilford Press.

Howard, G. (1994). ‘Why do people say nasty things about self-reports?' Journal of Organizational Behavior, 15: 5, 399-404.

Jiang, J., Wang, S. and Zhao, S. (2012). 'Does HRM facilitate employee creativity and organizational innovation? A study of Chinese firms'. International Journal of Human Resource Management, 23: 19, 4025-4047.

Jiang, K., Lepak, D.P., Hu, J. and Baer, J.C. (2012). 'How does human resource management influence organizational outcomes? A meta-analytic investigation of mediating mechanisms'. Academy of Management Journal, 55: 6, 1264-1294.

Jiménez-Jiménez, D. and Sanz-Valle, R. (2008). 'Could HRM support organizational innovation?' International Journal of Human Resource Management, 19: 7, 1208-1221.

Kang, S., Morris, S. and Snell, S. (2007). 'Relational archetypes, organizational learning, and value creation: Extending the human resource architecture'. Academy of Management Review, 32: 1, 236-256.

Kuvaas, B., Buch, R. and Dysvik, A. (2012). 'Perceived training intensity and knowledge sharing: Sharing for intrinsic and prosocial reasons'. Human Resource Management, 51: 2, 167-187.

Laursen, K. and Foss, N. (2003). 'New human resource management practices, complementarities and the impact on innovation performance'. Cambridge Journal of Economics, 27: 2, 243-263.

Laursen, K. and Foss, N. (2013). 'HRM and innovation', in M. Dodgson, D.M. Gann and N. Phillips (eds), The Oxford Handbook of Innovation Management, Oxford: Oxford University Press.

Lerchenmueller, M.J. and Nembhard, I.M. (2015). 'Incentives in the age of knowledge work'. Academy of Management Proceedings, doi:10.5465/AMBPP.2015.11727abstract. 
Levy, P.E. and Williams, J.R. (2004). 'The social context of performance appraisal: a review and framework for the future'. Journal of Management, 30: 6, 881-905.

Li, F., Deng, H., Leung, K. and Zhao, Y. (2016). 'Is perceived creativity-reward contingency good for creativity? The role of challenge and threat appraisals'. Human Resource Management. DOI:10.1002/ hrm.21795.

Liang, H., Saraf, N., Hu, Q. and Zue, Y. (2008). 'Assimilation of enterprise systems: The effect of institutional pressures and the mediating role of top management'. MIS Quarterly, 31: 1, 59-87.

Longenecker, C. O., Sims Jr, H. P., and Gioia, D. A. (1987). 'Behind the mask: The politics of employee appraisal'. Academy of Management Executive, 1: 3, 183-193.

Lopez-Cabrales, A., Pérez-Luño, A. and Cabrera, R.V. (2009). 'Knowledge as a mediator between HRM practices and innovative activity'. Human Resource Management, 48: 4, 485-503.

Lowry, P.B. and Gaskin, J. (2014). 'Partial least squares (PLS) structural equation modeling (SEM) for building and testing behavioral causal theory: When to choose it and how to use it'. IEEE Transactions on Professional Communication, 57: 2, 123-146.

March, J.G. (1991). 'Exploration and exploitation in organizational learning'. Organization Science, 2: 1, 71-87.

McGrath, R. (2001). 'Exploratory learning, innovative capacity and managerial oversight'. Academy of Management Journal, 44: 1, 118-131.

Medcof, J. and Song, L. (2013). 'Exploration, exploitation and human resource management practices in cooperative and entrepreneurial HR configurations'. International Journal of Human Resource Management, 24: 15, 2911-2926.

Minbaeva, D. (2013). 'Strategic HRM in building micro-foundations of organizational knowledge-based performance'. Human Resource Management Review, 23: 4, 378-390.

Minbaeva, D., Foss, N.J. and Snell, S. (2009). 'Bringing the knowledge perspective into HRM'. Human Resource Management, 48: 4, 477-483.

Minbaeva, D., Mäkelä, K. and Rabbiosi, L. (2012). ‘Linking HRM and knowledge transfer via individuallevel mechanisms'. Human Resource Management, 51: 3, 387-405.

Nishii, L., Lepak, D. and Schneider, B. (2008). 'Employee attributions of the "why" of HR practices: Their effects on employee attitudes and behaviours, and customer satisfaction'. Personnel Psychology, 61: 3, 503-545.

Nonaka, I. and Takeuchi, H. (1995). The Knowledge-creating Company, New York: Oxford University Press.

Osterloh, M. and Frey, B.S. (2000). 'Motivation, knowledge transfer, and organizational forms'. Organization Science, 11: 5, 538-550.

Paauwe, J. and Boselie, P. (2005). 'HRM and performance: What next?' Human Resource Management Journal, 15: 4, 68-83.

Paauwe, J. and Richardson, R. (1997). 'Introduction to special issue on HRM and performance'. International Journal of Human Resource Management, 3: 8, 257-262.

Park, R. and Kruse, D. (2014). 'Group incentives and financial performance: The moderating role of innovation'. Human Resource Management Journal, 24: 1, 77-94.

Podsakoff, P.M., MacKenzie, S.B. and Podsakoff, N.P. (2012). 'Sources of method bias in social science research and recommendations on how to control it'. Annual Review of Psychology, 63, 539-569.

Purcell, J. (1999). ‘Best practice and best fit: chimera or cul-de-sac?' Human Resource Management Journal, 9: 3, 26-41.

Ritala, P. and Hurmelinna-Laukkanen, P. (2013). 'Incremental and radical innovation in coopetition: The role of absorptive capacity and appropriability'. Journal of Product Innovation Management, 30: $1,154-169$.

Robinson, R.B. and Pearce, J.A. (1988). 'Planned patterns of strategic behaviour and their relationship to business-unit performance'. Strategic Management Journal, 9: 1, 43-60.

Sewell, G. (2005). 'Nice work? Rethinking managerial control in an era of knowledge work'. Organization, 12: 5, 685-704.

Shipton, H., Fay, D., West, M., Patterson, M. and Birdi, K. (2005). 'Managing people to promote innovation'. Creativity and Innovation Management, 14: 3, 118-128. 
Shipton, H., West, M.A., Dawson, J., Birdi, K. and Patterson, M. (2006). ‘HRM as a predictor of innovation'. Human Resource Management Journal, 16: 1, 3-27.

Spiller, S., Fitzsimmons, G., Lynch, J. and McClelland, G. (2013). 'Spotlights, floodlights, and the magic number zero: Simple effects tests in moderated regression'. Journal of Marketing Research, 50: 2, 277-288.

Sue-Chan, C. and Hempel, P.S. (2016). 'The creativity-performance relationship: How rewarding creativity moderates the expression of creativity'. Human Resource Management, 55: 4, 637-653.

Tomlinson, P.R. (2010). 'Co-operative ties and innovation: Some new evidence for UK manufacturing'. Research Policy, 39: 6, 762-775.

Tu, C. and Hall, G.C. (2004). 'Internationalization and size, age and profitability in the United Kingdom', in L.-P. Dana (ed.), Handbook of Research on International Entrepreneurship, Cheltenham: Edward Elgar.

Wasko, M.M. and Faraj, S. (2005). 'Why should I share? Examining social capital and knowledge contribution in electronic networks of practice'. MIS Quarterly, 29: 1, 35-57.

Zhao, Z.J. and Chadwick, C. (2014). 'What we will do versus what we can do: The relative effects of unit level NPD motivation and capability'. Strategic Management Journal, 35: 12, 1867-1880.

Zhou, K.Z. and Li, C.B. (2012). 'How knowledge affects radical innovation: Knowledge base, market knowledge acquisition, and internal knowledge sharing'. Strategic Management Journal, 33: 9, 1090-1102.

\section{APPENDIX: MEASUREMENT ITEMS}

\begin{tabular}{|c|c|c|c|c|c|}
\hline Concept & Item & Factor loading & AVE & CR & $\alpha$ \\
\hline HR practices & $\begin{array}{l}\text { To what extent do the following statements } \\
\text { on human resources management apply } \\
\text { to your company? }(1=\text { completely } \\
\text { disagree, } 5=\text { completely agree })\end{array}$ & & & & \\
\hline \multirow[t]{3}{*}{$\begin{array}{l}\text { Appraisal of knowledge } \\
\text { behaviours }\end{array}$} & $\begin{array}{l}\text { The sharing of information is one of } \\
\text { our criteria for work performance assessment. }\end{array}$ & $0.81^{* * *}$ & 0.72 & 0.89 & 0.81 \\
\hline & $\begin{array}{l}\text { The creation of new information is one of our } \\
\text { criteria for work performance assessment. }\end{array}$ & $0.85^{* * *}$ & & & \\
\hline & $\begin{array}{l}\text { The ability to apply information acquired } \\
\text { from others is one of our criteria for } \\
\text { work performance assessment. }\end{array}$ & $0.88^{* * *}$ & & & \\
\hline \multirow[t]{3}{*}{$\begin{array}{l}\text { Rewards for knowledge } \\
\text { behaviours }\end{array}$} & $\begin{array}{l}\text { Our company rewards employees for } \\
\text { sharing information. }\end{array}$ & $0.88^{* * *}$ & 0.79 & 0.92 & 0.87 \\
\hline & $\begin{array}{l}\text { Our company rewards employees for } \\
\text { creating new information. }\end{array}$ & $0.88^{* * *}$ & & & \\
\hline & $\begin{array}{l}\text { Our company rewards employees for } \\
\text { making use of information. }\end{array}$ & $0.91^{* * *}$ & & & \\
\hline Innovation & $\begin{array}{l}\text { Evaluate the effect of your innovation } \\
\text { operations on your company's net sales } \\
\text { over the past year }(1=\text { no effect, } 5= \\
\text { significant positive effect) }\end{array}$ & & & & \\
\hline Radical innovation & $\begin{array}{l}\text { Entirely new products or services } \\
\text { (radical innovation) }\end{array}$ & Single item measure & & & \\
\hline Incremental innovation & $\begin{array}{l}\text { Improved products or services } \\
\text { (incremental innovation) }\end{array}$ & Single item measure & & & \\
\hline
\end{tabular}


Copyright of Human Resource Management Journal is the property of Wiley-Blackwell and its content may not be copied or emailed to multiple sites or posted to a listserv without the copyright holder's express written permission. However, users may print, download, or email articles for individual use. 